\title{
MAPPING COASTAL AND WETLAND VEGETATION COMMUNITIES USING MULTI-TEMPORAL SENTINEL-2 DATA
}

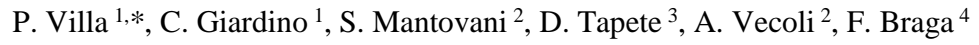 \\ ${ }^{1}$ Institute for Electromagnetic Sensing of the Environment, National Research Council (CNR-IREA), Milan, Italy - (villa.p, giardino.c)@irea.cnr.it \\ ${ }^{2}$ Meteorological and Environmental Earth Observation (MEEO), Ferrara, Italy - (vecoli, mantovani)@ meeo.it \\ ${ }^{3}$ Italian Space Agency (ASI), Rome, Italy - deodato.tapete@ asi.it \\ ${ }^{4}$ Institute of Marine Sciences, National Research Council (CNR-ISMAR), Venice, Italy - federica.braga@ ve.ismar.cnr.it
}

KEY WORDS: Salt marsh vegetation, Coastal vegetation, Classification, Decision trees, Synoptic seasonal features.

\begin{abstract}
:
Operational monitoring of complex vegetation communities, such as the ones growing in coastal and wetland areas, can be effectively supported by satellite remote sensing, providing quantitative spatialized information on vegetation parameters, as well as on their temporal evolution. With this work, we explored and evaluated the potential of Sentinel-2 data for assessing the status and evolution of coastal vegetation as the primary indicator of ecosystem conditions, by mapping the different plant communities of Venice lagoon (Northeast Italy) via a rule-based classification approach exploiting synoptic seasonal features of spectral indices and multispectral reflectance. The results demonstrated that coastal and wetland vegetation community type maps derived for two different years scored a good overall accuracy around $80 \%$, with some misclassification in the coastal areas and overestimation of salt marsh communities coverage, and that virtual collaborative environments can facilitate the use of Sentinel-2 data and products to multidisciplinary users.
\end{abstract}

\section{INTRODUCTION}

Coastal lagoons and wetlands are natural environments of great ecological and functional value, and are subject to numerous pressures of natural and anthropogenic origin. Because of their high dynamism, these ecosystems need frequent monitoring, in particular dealing with vegetation cover and diversity. Monitoring coastal and wetland vegetation requires a multidisciplinary approach (from ecology to hydrodynamics), that satellite remote sensing can support by providing quantitative information on vegetation features and dynamics (Ozesmi and Bauer, 2002, Adam et al., 2010; Klemas, 2013).

Approaches based on spectral indices derived from multispectral optical satellite data have demonstrated an effective solution for monitoring complex ecosystems, due to their straightforwardness, efficiency (e.g. by reducing data redundancy), and ease of direct interpretation of results. Approaches based on spectral indices derived from midresolution multispectral satellite data as input (e.g. Landsat series) have been successfully used for different applications covering terrestrial and aquatic vegetation groups in freshwater and brackish systems, such as mapping cover and distinguishing plant community types (Davranche et al., 2010, Villa et al., 2015), assessing their functional status (Dronova et al., 2012; Villa et al., 2013; Hestir et al., 2015), assessing the impact of natural hazards (Villa et al., 2012), and monitoring tidal wetlands (Ozesmi and Bauer, 2002; Ghosh et al., 2016).

The availability of dense time series of Sentinel-2 data (Copernicus EO programme), provides new capabilities for deriving vegetation community. Sentinel-2 constellation is a step forward in terms of spatial (10 m resolution), spectral (13 spectral bands) and temporal (5 days revisiting time) coverage capabilities required for effective, operational monitoring of coastal ecosystems, in terms of reliability (i.e. thematic accuracy) and information content (i.e. semantic classification level) compared to what has been so far operationally feasible.
The objectives of this work, part of the costeLAB project (Tapete et al., 2021) supported by the Italian Space Agency (ASI), were to evaluate the potential of Sentinel-2 data for assessing the status and evolution of vegetation communities, as a primary indicator of lagoon ecosystem conditions, and to outline the potential of a virtual lab environment for collaborative coastal research.

\section{MATERIALS AND METHODS}

Coastal and wetland vegetation communities of Venice Lagoon (Northeast Italy) were mapped following the approach developed by Villa et al. (2015). Venice Lagoon is the largest lagoon in Italy, covering an area of around $550 \mathrm{~km}^{2}$, with average depth around $1 \mathrm{~m}$. It is characterized by a semidiurnal tidal regime with an average value of $\pm 0.7 \mathrm{~m}$. Its heterogeneous morphology is characterized by a mixed pattern of major (navigable) and minor channels, salt marshes, tidal flats and islands, which have been artificially modified by man throughout the centuries. The lagoon consists of a complex mosaic of different vegetation, depending mainly on land elevation, water salinity and freshwater input. The salt marshes are dominated by different halophytic species (e.g. Spartina maritima, Suaeda maritima, Salicornia fruticosa), while marginal freshwater sectors are dominated by herbaceous helophytes, in particular Phragmites australis, with Juncus maritimus as dominant species at intermediate conditions. Coastal dunes and areas along the shoreline of the Adriatic Sea are mainly populated by short herbaceous species, either shifting or fixed, with some small patches of coastal forest dominated by Pinus pinea.

\subsection{Reference set}

Spatial distribution information included into habitat maps of Venice lagoon following Natura 2000 nomenclature was used to compile a reference dataset of vegetation community types (Table 1).

\footnotetext{
* Corresponding author
} 


\begin{tabular}{|c|c|c|c|c|c|c|}
\hline Level 1 Class & $\begin{array}{l}\text { L1 } \\
\text { ID }\end{array}$ & Color & Level 2 Class & $\begin{array}{l}\text { L2 } \\
\text { ID }\end{array}$ & Dominant species & $\begin{array}{l}\text { Habitat } \\
\text { (Natura } \\
\text { 2000) }\end{array}$ \\
\hline $\begin{array}{l}\text { Optically shallow } \\
\text { water }\end{array}$ & 1 & & water & 10 & - & - \\
\hline \multirow{2}{*}{$\begin{array}{l}\text { Optically deep } \\
\text { water }\end{array}$} & \multirow[t]{2}{*}{2} & & mud/sand bottom & 21 & - & 1140 \\
\hline & & & submerged vegetation & 22 & Zostera marina, Zostera noltii, Cymodocea nodosa & 1140,1150 \\
\hline \multirow[t]{3}{*}{$\begin{array}{l}\text { Herbaceous salt } \\
\text { marsh vegetation }\end{array}$} & \multirow[t]{3}{*}{3} & & pioneer marsh vegetation & 31 & $\begin{array}{l}\text { Cakile maritima, Kali turgidum, Suaeda maritima, } \\
\text { Salicornia veneta }\end{array}$ & 1210,1310 \\
\hline & & & herbaceous marsh vegetation & 32 & $\begin{array}{l}\text { Puccinellia festuciformis, Spartina maritima, Spartina } \\
\text { x townsendii, Juncus maritimus, Juncus acutus }\end{array}$ & 1320,1410 \\
\hline & & & shrub (short) marsh vegetation & 33 & $\begin{array}{l}\text { Sarcocornia fruticose, Suaeda maritima, Halimione } \\
\text { portulacoides, Limonium narbonense, }\end{array}$ & 1420,1510 \\
\hline \multirow[t]{2}{*}{$\begin{array}{l}\text { Herbaceous } \\
\text { coastal vegetation }\end{array}$} & \multirow[t]{2}{*}{4} & & $\begin{array}{l}\text { shifting herbaceous coastal } \\
\text { vegetation }\end{array}$ & 41 & $\begin{array}{l}\text { Elymus farctus, Sporobolus pungens, Ammophila } \\
\text { arenaria, Echinophora spinosa }\end{array}$ & 2110,2120 \\
\hline & & & $\begin{array}{l}\text { fixed herbaceous coastal } \\
\text { vegetation }\end{array}$ & 42 & $\begin{array}{l}\text { Silene colorata, Vulpia membranacea, Cerastium } \\
\text { semidecandrum, Eryngium maritimum, Tortula ruralis, } \\
\text { Scabiosa argentea, Malcomia spp. }\end{array}$ & 2130,2230 \\
\hline Helophytes & 5 & & helophytic (wetland) vegetation & 50 & Phragmites australis & - \\
\hline \multirow[t]{2}{*}{ Coastal forest } & \multirow[t]{2}{*}{6} & & deciduous woody vegetation & 61 & Populus spp., Robinia pseudoacacia, Rubus ulmifolius & $92 \mathrm{~A} 0$ \\
\hline & & & evergreen woody vegetation & 62 & Pinus pinea, Pinus pinaster & 2270 \\
\hline Other grassland & 7 & & $\begin{array}{l}\text { grasses (including. areas subject } \\
\text { to anthropogenic disturbance) }\end{array}$ & 70 & $\begin{array}{l}\text { Bromus sterilis, Dasypyrum villosum, Chenopodium } \\
\text { album, Cynodon dactylon, Artemisia verlotorum, } \\
\text { Melilotus alba, Silene colorata, Elytrigia atherica }\end{array}$ & 6420 \\
\hline Barren land & 8 & & $\begin{array}{l}\text { sand beaches, rocks and exposed } \\
\text { sediments }\end{array}$ & 80 & - & - \\
\hline
\end{tabular}

Table 1. Thematic classification scheme adopted for mapping Venice lagoon vegetation community type, with corresponding Natura 2000 habitat nomenclature and dominant species present for each class.

Habitat types were first grouped into 11 classes (Level 2), which were then aggregated into 6 higher level classes (Level 1). For training and validating the classifier, we first randomly sampled 1000 points $(10 \times 10 \mathrm{~m}$ pixels, consistent with Sentinel-2 resolution) for each Level 2 (L2) class, and then we checked the 1000 points against vegetation conditions in 2016 and 2017, by excluding points not covered by natural vegetation. Finally, we aggregated classes at Level 1 (L1) and divided the whole reference set into subsets to be used for different classification tests: test A - composed by training set ( $2 / 3$ of points of 2016 set, for each L1 class), validation set (1/3 of points of 2016 set, for each L1 class), and transferability test set (all points of 2017 set); and test B - composed by training set ( $2 / 3$ of points of 2016 and 2017 merged sets, for each L1 class), and validation set (1/3 of points of 2016 and 2017 merged sets, for each L1 class). In the end, the L1 classification scheme featured 8 classes: optically deep water, optically shallow water, herbaceous salt marsh vegetation, herbaceous coastal vegetation, helophytes, coastal forest, other grassland, barren land.

\subsection{Satellite data processing and assessment}

Sentinel-2 (Sentinel-2A satellite) data for 2016 and 2017 seasons, with cloud cover less than $50 \%$, were gathered and converted to surface reflectance using SEN2COR (Louis et al., 2016). From the dataset, time series of two spectral indices sensitive to vegetation features were derived, namely the Water Adjusted Vegetation Index (WAVI), developed specifically to maximize the sensitivity to the density and biomass of aquatic vegetation (Villa et al., 2014), and the Normalized Difference Flood Index (NDFI), providing information about soil moisture and flooding conditions of vegetated areas (Boschetti et al., 2014). Synoptic seasonal features of WAVI and NDFI - i.e. minimum, maximum, mean and standard deviation - were derived from the time series for the whole year as well as for three seasonal windows: i) early spring period, centred on April (DOY 85-125); ii) full summer period, ranging from mid-July to late August (DOY 190-250); iii) late autumn period, ranging from mid-October to mid-November (DOY 280-325).

Synoptic features were joined with multispectral reflectance at peak of season conditions (from Sentinel-2 acquired on 27 August 2016 and 02 August 2017) and used as input for mapping vegetation communities in both years, using a supervised hierarchical set of cascade rules structured in a binary tree (Quinlan, 1996). For minimizing over-fitting issues, the minimum number of classified instances per each node was set to 100 for test $\mathrm{A}$ and 200 for test $\mathrm{B}$, less of half the size of the smallest class in the training set. The rule-based classification tree was trained using the training set at L1 classes (7031 pixels for test A, 13404 for test B), and its accuracy calculated using an independent validation set (3515 pixels for test A, 6701 for test B).

To this end, both overall metrics, i.e. Overall Accuracy (OA) and Cohen's Kappa (Kappa), as well as per class metrics, i.e. Fmeasure (CA), were calculated (Foody, 2002).

For test A, the temporal transferability of the method calibrated with 2016 dataset was in the end evaluated by applying the approach to synoptic seasonal features derived from Sentinel-2 time series of 2017, thus producing the 2017 map of vegetation communities and assessing its accuracy over the whole 2017 reference set (9559 pixels).

\subsection{Virtual environment}

Tests were carried out within the Virtual Lab of costeLAB project, a virtual environment based on Docker containers meant to facilitate reproducible, multidisciplinary and collaborative research in sharing data and resources, developing novel applications and demonstrating products for coastal risk monitoring and management. The Virtual Lab is offered as a web-based interactive interface for live coding of Jupyter notebooks: it includes IPython development environment, and allows the use of Python, $\mathrm{R}$ and Fortran as programming languages. 

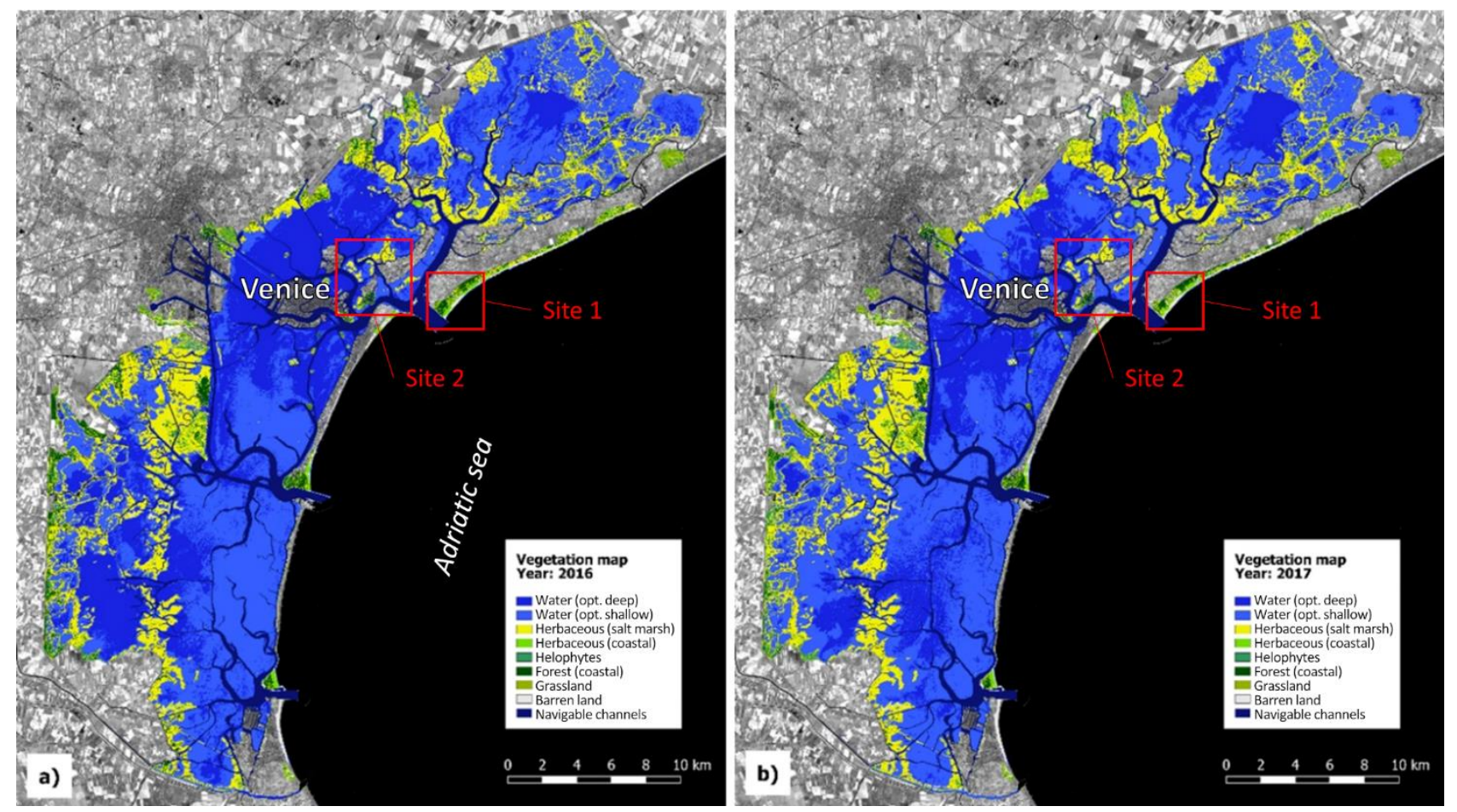

Figure 1. Vegetation community type maps derived from Sentinel-2 time series using the integrated 2016-2017 data (test B), representing vegetation cover in Venice lagoon: a) 2016 season; b) 2017 season.
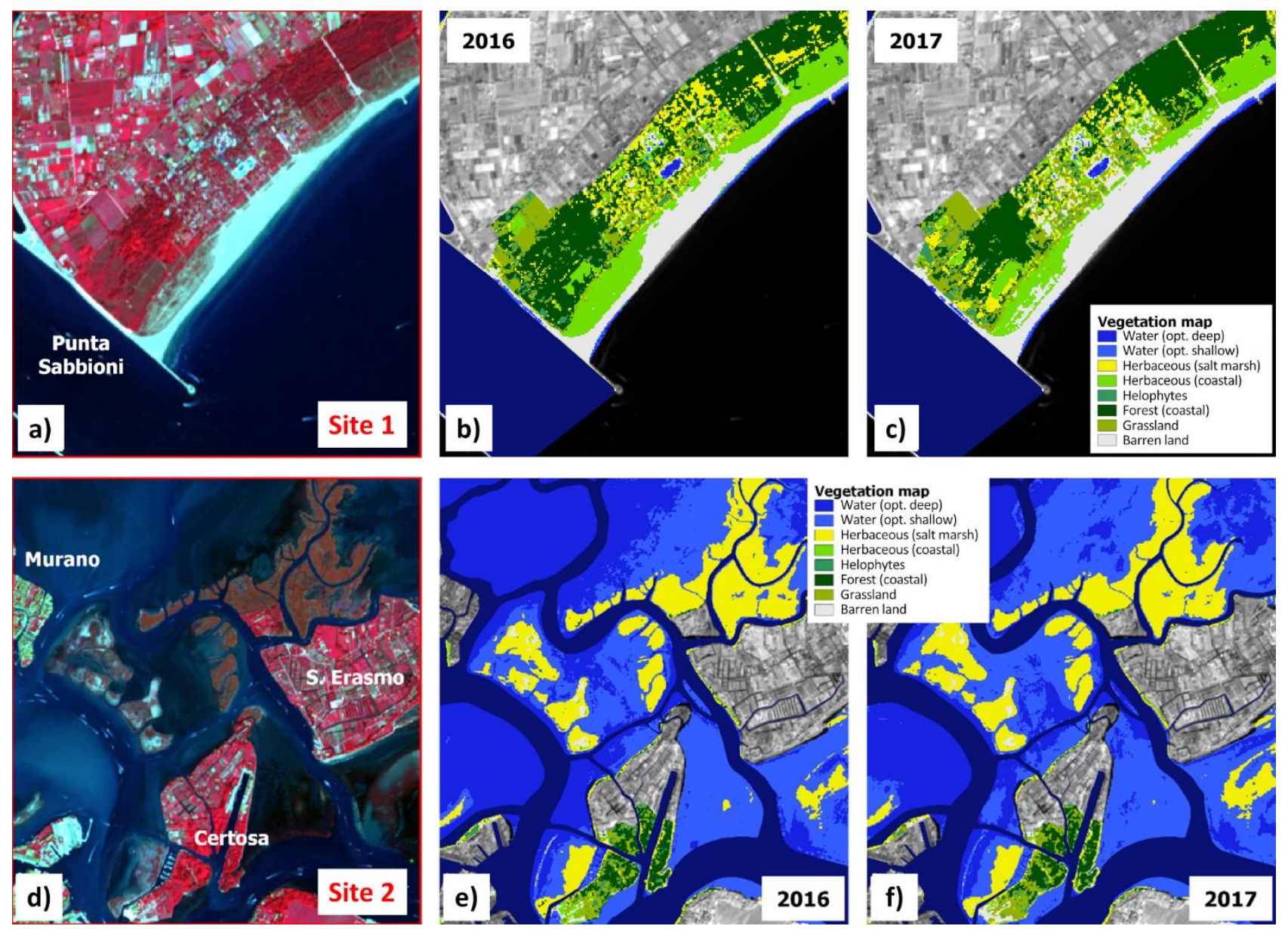

Figure 2. Details of the vegetation community maps of the Venice lagoon for two sites (Site 1 and Site 2, locations shown in Figure 1). Site 1 is located in the area of Punta Sabbioni, and Site 2 is located between Murano and S. Erasmo islands: colour infrared RGB composition of Sentinel-2 scene of 27 August 2016 (a, d); vegetation community type maps of 2016 (b, e) and 2017 (c, f). 


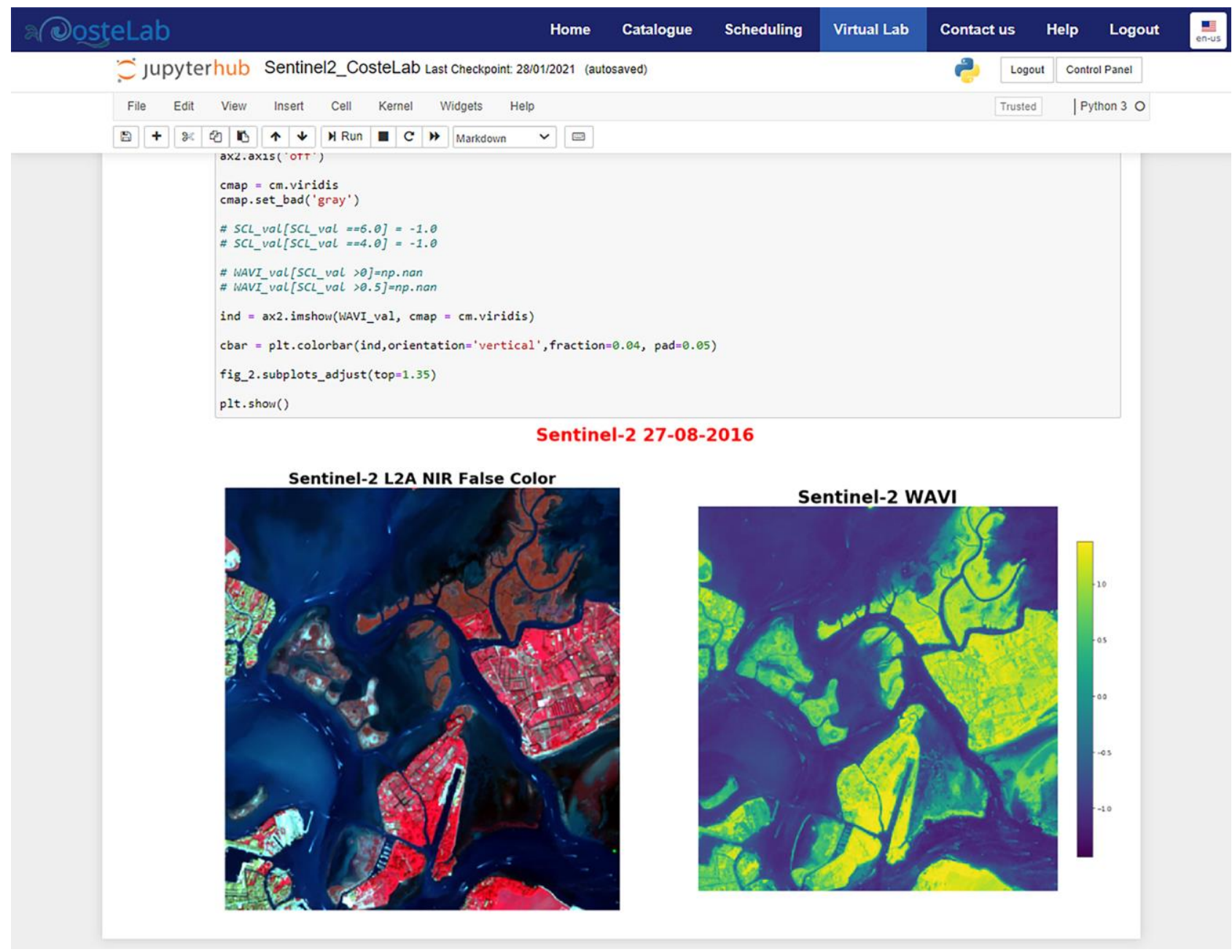

Figure 3. Output of a Sentinel-2 product processing, as displayed in a Jupyter Notebook of the Virtual Lab.

Therein, researchers can access satellite data, exploit computing resources, run predefined image processing routines, share or develop their own codes, e.g. to directly source Sentinel-2 collections from Copernicus Open Access Hub and undertake spectral analysis across a selected time series. Further processing can be implemented by using the set of open source software packages that are available in the Virtual Lab (e.g. GDAL, ESA SNAP).

\section{RESULTS AND DISCUSSION}

The vegetation community classification algorithm was run under test $\mathrm{A}$ and test $\mathrm{B}$ conditions and vegetation community type maps of Venice lagoon were produced for 2016 and 2017 seasons (Figure 1).

The comparison between the accuracy assessment results derived from the independent 2016 validation set and the 2017 (test A) shows a generally good accuracy for the 2016 , with $\mathrm{OA}=80.6 \%$ and Kappa $=0.771$ calculated over the independent validation set. When the rules implemented starting from 2016 training set are applied to the same features derived from 2017 Sentinel-2 data, the overall accuracy decreases to $65.5 \%$. This suggests that interannual variations in the input features must be considered if temporal transferability of the method is targeted.

The temporal inconsistency highlighted from test A outcomes was tackled by running the classification experiment under test $\mathrm{B}$ conditions.

The accuracies of the vegetation community type maps produced for 2016 and 2017 were generally good and highly consistent
(Table 2), i.e. with $\mathrm{OA}=78.9 \%(\mathrm{Kappa}=0.751)$ and $\mathrm{OA}=79.1 \%$ (Kappa $=0.754$ ) for 2016 and 2017, respectively, and differences in per-class accuracies between the years lower than 0.10 .

The classes most accurately mapped, with CA higher than $80 \%$, were barren land $(C A>0.89)$, herbaceous salt marsh vegetation $(\mathrm{CA}>0.86)$, optically shallow water $(\mathrm{CA}>0.84)$. Coastal herbaceous vegetation $(\mathrm{CA}>0.77)$ and optically deep water $(\mathrm{CA}>0.69)$ were mapped with good reliability.

Sub-par accuracies (CA>0.63) are scored for helophytes (mostly common reed patches in riparian areas) and coastal forest, while the most problematic class is grassland $(\mathrm{CA}<0.50)$. Even if the overall performance is slightly under $80 \%$ in OA, the consistency across two years suggests good chances of temporal transferability of the approach.

Figure 2a-c shows an example of high detail extract of the vegetation community type maps over the coastal area of Punta Sabbioni $\left(45^{\circ} 26^{\prime} 51^{\prime \prime} \mathrm{N}, 12^{\circ} 25^{\prime} 31^{\prime \prime}\right.$ E; see location in Figure 1), where natural vegetation is dominated by herbaceous-shrub communities growing on sand dunes and the coastal forest of the backshore area. The main vegetation classes (herbaceous coastal vegetation and coastal forest) are well delineated, as well as the beach sands correctly mapped as barren land. Some misclassification is evident in correspondence of camping sites where the presence of bungalows and tents intermingled with Pinus spp. Figure 2d-f shows another example of high detail extract of the vegetation community type maps of Figure 1, this time representing the salt marshes located in the north-eastern part of the lagoon, between Murano and S. Erasmo islands $\left(45^{\circ} 27^{\prime} 29^{\prime \prime} \mathrm{N}, 12^{\circ} 23^{\prime} 07^{\prime \prime} \mathrm{E}\right)$, where dominant natural vegetation 
is composed by herbaceous communities of halophyte species growing in the intertidal zone. The main vegetation class here, herbaceous salt marsh vegetation, is well delineated, together with some bare sediment areas correctly mapped as barren land. Moreover, the mosaic of trees and grassland of Certosa island, visible in the lower part of Figure 2e-f, is correctly classified. Finally, an example of the use of costeLAB Virtual Lab is provided in Figure 3, which shows the Sentinel-2 NIR RGB image and the WAVI map of the scene for one of the selected dates. The maps are obtained in a Jupyter Notebook, where SEN2COR has been used to obtain the atmospherically corrected L2A product, and the NIR RGB image and the WAVI map have been produced with the Python module of ESA SNAP available in the Virtual Lab.

\begin{tabular}{|c|c|c|c|c|c|c|c|c|c|}
\hline \multicolumn{10}{|c|}{ Mapped class (2016) } \\
\hline & W_d & W_s & $\mathrm{Hb} \_\mathrm{s}$ & Hb_c & Helo & $\mathrm{Fr}$ & Gl & $\mathrm{Bl}$ & $C A$ \\
\hline W_d & 257 & 83 & 0 & 0 & 0 & 0 & 0 & 0 & 0.75 \\
\hline W_s & 84 & 576 & 19 & 0 & 0 & 0 & 0 & 0 & 0.86 \\
\hline 恚 Hb_s & 0 & 9 & 756 & 7 & 15 & 59 & 5 & 3 & 0.86 \\
\hline $\begin{array}{l}\tilde{J} \\
\dot{\delta}\end{array}$ & 0 & 0 & 27 & 349 & 10 & 61 & 26 & 5 & 0.81 \\
\hline 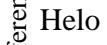 & 0 & 0 & 34 & 2 & 172 & 21 & 34 & 0 & 0.64 \\
\hline$\widetilde{\mathscr{d}} \mathrm{Fr}$ & 0 & 0 & 37 & 13 & 30 & 251 & 40 & 2 & 0.63 \\
\hline Gl & 0 & 0 & 18 & 16 & 43 & 28 & 103 & 3 & 0.49 \\
\hline $\mathrm{B} 1$ & 0 & 1 & 5 & 1 & 0 & 0 & 0 & 310 & 0.97 \\
\hline \multicolumn{10}{|c|}{ Mapped class (2017) } \\
\hline & W_d & W_s & Hb_s & Hb_c & Helo & $\mathrm{Fr}$ & Gl & $\mathrm{Bl}$ & $C A$ \\
\hline W_d & 191 & 92 & 0 & 0 & 0 & 0 & 0 & 0 & 0.69 \\
\hline W_s & 77 & 469 & 4 & 0 & 0 & 0 & 0 & 0 & 0.84 \\
\hline 恚 Hb_s & 0 & 5 & 733 & 9 & 22 & 15 & 6 & 7 & 0.91 \\
\hline $\begin{array}{l}\bar{\delta} \\
\dot{\Xi}\end{array}$ & 0 & 0 & 30 & 304 & 14 & 18 & 40 & 38 & 0.77 \\
\hline 预 Helo & 0 & 0 & 20 & 2 & 179 & 17 & 34 & 2 & 0.69 \\
\hline$\stackrel{\square}{\mathscr{d}} \mathrm{Fr}$ & 0 & 0 & 10 & 9 & 21 & 249 & 70 & 11 & 0.73 \\
\hline $\mathrm{Gl}$ & 0 & 0 & 16 & 19 & 29 & 17 & 114 & 7 & 0.49 \\
\hline B1 & 0 & 0 & 5 & 0 & 0 & 0 & 0 & 281 & 0.89 \\
\hline
\end{tabular}

Table 2. Confusion matrix of the vegetation community type maps calculated on the independent validation sets for 2016 (upper panel) and 2017 (lower panel). W_d: Water (opt. deep); W_s: Water (opt. shallow); Hb_s: Herbaceous (salt marsh); Hb_c: Herbaceous (coastal); Helo: Helophytes; Fr: Forest (coastal); Gl: Grassland; Bl: Barren land.

\section{CONCLUSIONS}

The findings presented demonstrate that spectral and temporal information summarized into synoptic seasonal features derived from Sentinel-2 time series - even with a reduced revisit, compared to the maximum nominal resolution of 5 days (Sentinel-2A plus 2B) - can be effectively used for assessing the status of coastal and wetland vegetation as primary indicator of ecosystem conditions. Retuning of classification rules, by incorporating training samples relative to different years, is needed in order to promote the temporal transferability of the method to different growing seasons, in particular for enhancing discrimination between open water and short salt marsh vegetation.

Vegetation community type maps derived for the years 2016 and 2017 have generally provided a reliable picture of Venice lagoon vegetation, with an overall accuracy around $80 \%$, while some minor misclassification issues were registered for vegetation classes of more terrestrial habit (trees and grassland). Furthermore, the capabilities of the virtual collaborative environment developed within the costeLAB project proved useful for facilitating the use of Sentinel-2 data and products to multidisciplinary, non-expert users.

\section{ACKNOWLEDGEMENTS}

This work was supported by the Italian Space Agency (ASI) with the project costeLAB (Contract Number 2017-I-E.0). We are grateful to E. Lopinto (ASI) and M. Palandri (e-GEOS) for having promoted and supported this research.

\section{REFERENCES}

Adam, E., Mutanga, O., \& Rugege, D. (2010). Multispectral and hyperspectral remote sensing for identification and mapping of wetland vegetation: a review. Wetlands Ecology and Management, 18(3), 281-296.

Boschetti, M., Nutini, F., Manfron, G., Brivio, P. A., \& Nelson, A. (2014). Comparative analysis of normalised difference spectral indices derived from MODIS for detecting surface water in flooded rice cropping systems. PloS one, 9(2), e88741.

Davranche, A., Lefebvre, G., \& Poulin, B. (2010). Wetland monitoring using classification trees and SPOT-5 seasonal time series. Remote Sensing of Environment, 114(3), 552-562.

Dronova, I., Gong, P., Clinton, N. E., Wang, L., Fu, W., Qi, S., \& Liu, Y. (2012). Landscape analysis of wetland plant functional types: The effects of image segmentation scale, vegetation classes and classification methods. Remote Sensing of Environment, 127, 357-369.

Foody, G. M. (2002). Status of land cover classification accuracy assessment. Remote Sensing of Environment, 80(1), 185-201.

Ghosh, S., Mishra, D. R., \& Gitelson, A. A. (2016). Long-term monitoring of biophysical characteristics of tidal wetlands in the northern Gulf of Mexico-A methodological approach using MODIS. Remote Sensing of Environment, 173, 39-58.

Hestir, E. L., Brando, V. E., Bresciani, M., Giardino, C., Matta, E., Villa, P., \& Dekker, A. G. (2015). Measuring freshwater aquatic ecosystems: The need for a hyperspectral global mapping satellite mission. Remote Sensing of Environment, 167, 181-195.

Klemas, V. (2013). Remote sensing of coastal wetland biomass: An overview. Journal of Coastal Research, 29(5), 1016-1028.

Louis, J., Debaecker, V., Pflug, B., Main-Knorn, M., Bieniarz, J., Mueller-Wilm, U., ... \& Gascon, F. (2016). Sentinel-2 sen2cor: L2a processor for users. In Proceedings Living Planet Symposium 2016 (pp. 1-8).

Ozesmi, S. L., \& Bauer, M. E. (2002). Satellite remote sensing of wetlands. Wetlands ecology and management, 10(5), 381-402.

Quinlan, J. R. (1996). Improved use of continuous attributes in C4.5. Journal of artificial intelligence research, 4, 77-90.

Tapete, D., Candela, L., Coletta, A., Daraio, M.G., Guarini, R., Lopinto, E., Palandri, M., Pellegrino, D., Amodio, A., Giardino, C., \& Bresciani, M. (2021). costeLAB, the Italian thematic 
platform for coastal and marine downstream applications of institutional and research users in the context of Copernicus data exploitation. EGU General Assembly 2021, doi: 10.5194/egusphere-egu21-7069

Villa, P., Boschetti, M., Morse, J. L., \& Politte, N. (2012). A multitemporal analysis of tsunami impact on coastal vegetation using remote sensing: a case study on Koh Phra Thong Island, Thailand. Natural Hazards, 64(1), 667-689.

Villa, P., Laini, A., Bresciani, M., \& Bolpagni, R. (2013). A remote sensing approach to monitor the conservation status of lacustrine Phragmites australis beds. Wetlands Ecology and Management, 21(6), 399-416.

Villa, P., Mousivand, A., \& Bresciani, M. (2014). Aquatic vegetation indices assessment through radiative transfer modeling and linear mixture simulation. International Journal of Applied Earth Observation and Geoinformation, 30, 113-127.

Villa, P., Bresciani, M., Bolpagni, R., Pinardi, M., \& Giardino, C. (2015). A rule-based approach for mapping macrophyte communities using multi-temporal aquatic vegetation indices. Remote Sensing of Environment, 171, 218-233. 